\title{
ORGANIZANDO LA ESPERANZA: UTOPÍAS CONCRETAS PLURIVERSALES CONTRA Y MÁS ALLÁ DE LA FORMA VALOR*
}

\author{
Ana Cecilia Dinerstein ${ }^{1}$
}

\begin{abstract}
RESUMEN: ¿Cuál es la forma que adopta la utopía hoy? Mediante el establecimiento de una afinidad electiva entre autonomía y el principio de esperanza de Bloch, la autora de este trabajo define autonomía como 'el arte de organizar la esperanza’. Esa es una utopía concreta que desafía los parámetros de legibilidad de la realidad dada: niega, crea, entra en contradicción con, contra, y más allá del Estado, y produce un 'excedente' intraducible en el lenguaje capitalista, patriarcal y colonial. El principio esperanza acerca las prácticas autónomas indígenas y no indígenas. Ambas son utopías pluriversales, que navegan en las venas abiertas del capital, oponiéndole a su existencia invisible otras realidades que 'todavía no han llegado a ser', pero pueden anticiparse, iluminando así la oscuridad del presente.
\end{abstract}

Palabras clave: Movimientos sociales e indígenas. Pluriversalidad. Utopía concreta. Valor. Esperanza.

\section{ORGANIZING HOPE: PLURIVERSAL CONCRETE UTOPIAS AGAINST AND BEYOND THE VALUE FORM}

\begin{abstract}
What is the form of utopia today? By establishing an elective affinity between autonomy and Bloch's hope principle, the author of this paper defines autonomy as 'the art of organising hope'. It is a 'concrete utopia' that challenges the parameters of legibility of certain reality: denies, creates, contradicts with, against and beyond the State, and produces an untranslatable surplus in the capitalist, patriarchal, and colonial language. The principle of hope connects indigenous and non-indigenous autonomous practices. Both are pluriversal utopias that navigate within the open veins of capital by opposing to its invisible existence some alternative realities that 'have not yet', but can be anticipated thus illuminating the darkness of the present.
\end{abstract}

Keywords: Social and indigenous movements. Pluriversality. Concrete utopia. Value. Hope.

\footnotetext{
*Este artículo se basa en una ponencia presentada en la Segunda Convención Internacional de Verano "La democratización del espacio", organizada por el Centro de Estudios Nacionales de Derecho al Territorio (CENEDET, IAEN), Quito, 3-14 de agosto 2015. El trabajo está inspirado en una investigación en curso sobre movimientos sociales y pedagogías alternativas en Brasil y Reino Unido en colaboración con el doctor Paolo Vittoria de la Universidad Federal de Rio de Janeiro. La autora agradece a la Academia Británica (British Academy, Newton Mobility Grant) por su apoyo financiero para la investigación (Research Grant RC-SP1089/2015-2016).

${ }^{1}$ Universidad de Bath, Reino Unido. E-mail: A.C.Dinerstein@bath.ac.uk

DOI: 10.1590/ES0101-73302016162414
} 


\title{
EN ORGANISANT L'ESPOIR: UTOPIES CONCRÈTES PLURIVERSELLES CONTRE ET AU-DELÀ DE LA FORME VALEUR
}

\begin{abstract}
RESUME: Quelle forme l'utopie a pris aujourd'hui? En établissant une affinité élective entre l'autonomie et le principe d'espoir de Bloch, L'auteur de cet article définit autonomie comme «l'art d'organiser l'espoir». L'autonomie est une utopie concrète qui remet en question les paramètres de la lisibilité de la réalité donnée: il nie, croire, contredit, contre et au-delà de l'état, et produit un excédent intraduisible dans le langue capitaliste, patriarcale et coloniale. Le principe de l'espoir lie les pratiques autonomes indigènes et non-indigènes. Ces sont utopies pluriverselles. Les deux suivent les cours du capital, en opposant son existence invisible d'autres réalités qui ne sont pas encore atteint, mais peuvent être anticipés, donc éclairer l'obscurité du présent.
\end{abstract}

Mots-clés: Ernst Bloch. La contradiction. La déception. L'espoir. L'excédent. Les mouvements sociaux et indigènes. Pluriversalité. Traduction. Utopie concrète. Valeur.

\section{La utopía hoy: autonomía y esperanza}

¿Cuál es la forma específica que adopta la utopía hoy? Intentar contestar a esta pregunta incansable es una tarea de gran responsabilidad, justamente porque a pesar de que existe una gran desilusión con las formas tradicionales de la política y del pensamiento radical y una crisis civilizatoria, paradójicamente (o quizá necesariamente) también vivimos en tiempos utópicos. Claramente, la utopía de hoy ya no es una idea abstracta elaborada por la vanguardia del partido que se lograra en el 'futuro'. La utopía actual es una práctica concreta y cotidiana de millones de personas comprometidas por la creación de un mundo plural y digno contra y más allá del neoliberalismo global. En este trabajo, se propone que para reconocer a la utopía concreta y apreciar su importancia, trasladar su mirada desde el ámbito político-institucional hacia el de la sociedad. No ueire decir en absoluto dejar de lado al Estado y a las instituciones sino cambiar el foco del presente análisis. Los cambios significativos en la acción de los movimientos sociales pueden guiarnos para enfoque sobre el papel de las prácticas autónomas en la construcción de la utopía.

En América Latina, la esperanza renació en los años 1990 de las cenizas de la destrucción neoliberal cuando movilizaciones, huelgas, tomas de tierras y ocupaciones, resistencias articuladas, protagonizadas por un sujeto nuevo y plural irrumpieron con fuerza contra el ajuste neoliberal salvaje en la región. La esperanza tuvo que ser reaprendida y organizada. Esto es todo un arte, sobre todo por las condiciones de represión y pobreza en las que las luchas contra y más allá de la globalización 
neoliberal colonial estuvieron y están sumergidas. Estas disputas son el punto de partida concreto para el análisis pues nos brindan la oportunidad de generar nuevos o renovados horizontes, ideas y prácticas que no solo se oponen al capitalismo colonial y patriarcal, sino que lo superan en muchos aspectos. Son una fuente de inspiración. Esto es particularmente importante en este momento del mundo. Como sugieren los ecologistas políticos brasileńos Porto-Gonçalves y Leff (2015), la crisis actual como de civilización pone "un límite en la progresión de la modernidad y abre nuevos horizontes de civilización en la perspectiva de la sostenibilidad" (p. 66). Los autores sostienen que se requiere de "la deconstrucción de las teorías y prácticas edificadas sobre los fundamentos de la racionalidad científica, económica, tecnológica y política de la modernidad, inscritas es las instituciones nacionales e internacionales del mundo globalizado [...]" (PORTO-GONCALVES, LEFF 2015, p. 66).

El interés por explorar los significados y el potencial político de la autonomía ha crecido como resultado de las luchas contra la globalización neoliberal, que transformaron a la región en un laboratorio político de la resistencia autónoma como estrategia revolucionaria a fin de siglo. Experimentando con nuevas formas de auto-organización, auto-representación, autodeterminación y autogestión, los movimientos autónomos se embarcaron en una construcción compleja y prometedora, conservando una distancia relativa (discursiva y también práctica) respecto del Estado y otras formas institucionalizadas de participación y lucha (DINERSTEIN, 2013).

El neoliberalismo generó un imaginario regional de desesperanza y miedo, los cuales son instrumentos clave para la implementación de políticas de ajuste y austeridad. Este simbolismo de desesperanza y miedo fue construido materialmente a través de una serie de políticas, discursos, mecanismos, leyes y acciones políticas que erigieron al neoliberalismo como la única realidad. Como indica Kaminsky (1998) en su estudio sobre Spinoza, "todos estos ideólogos de las 'pasiones tristes' son los que supieron torcer las vidas para que los hombres 'luchen por su esclavitud como si fuera por su libertad"' (p. 21).

Se puede comenzar con el aniquilamiento físico, la tortura y el exilio forzado por dictaduras militares de un nuevo tipo de una generación de soñadores revolucionarios - equivocados o no - ; luego, la creación de la deuda externa y el consecuente gobierno por endeudamiento (LAZZARATO 2013). A esto se sumó la 'desaparición virtual del trabajo', es decir, el pasaje de la aniquilación física del enemigo a su desaparición como agente del cambio social a través del desempleo, de la exclusión social, la represión política, la mercantilización de los ejidos y la intensificación del uso de la tierra para especulación financiera y el agronegocio.

Sin embargo, el elemento más importante en la construcción social de la desesperanza fue la utilización de la democracia y leyes para legitimar el terrorismo del dinero en nombre de la estabilidad. A diferencia de los gobiernos dictatoria- 
les, los democráticos neoliberales concedieron un estatus legal a la subordinación política a la ley del valor. Esta paradoja es solo aparente cuando se piensa que en el capitalismo global el logro temporario de la llamada estabilidad financiera siempre requiere de la desestabilización de la vida de las personas. Tanto Grecia como Argentina son ejemplos contundentes de esto. La legitimación y legalización del terrorismo del dinero hacen que el uso de la violencia estatal se vuelva cotidiana a través de políticas públicas que se anuncian ser para el bien común, pero son en realidad mecanismos para transferir recursos desde los pueblos a las grandes transnacionales, una y otra vez, sin límites.

Decepcionados con el Estado y la política del neoliberalismo, y a diferencia del pasado, las nuevas luchas autónomas emergidas a finales de los 1990 depositaron la ilusión política en sí mismas y en sus prácticas anticipadoras de mundos alternativos y dignos. Los movimientos sociales del mundo transitaron una etapa donde dejaron de demandar al Estado para ser creadores de nuevos horizontes y realidades. Más allá de las diferencias, las experiencias autónomas del presente comparten una característica fundamental: combinan nuevas formas concretas de intervención social, producción y organización, por un lado, con una proyección política de espíritu emancipador cuestionadora no ya de la forma, sino los fundamentos del capitalismo patriarcal y colonial, por el otro. En manos de estas subjetividades rebeldes, la autonomía colectiva deviene simultáneamente un instrumento para oponerse a la miseria social producida por el neoliberalismo, a la vez que permite soñar en forma práctica (imaginar y anticipar) formas relacionales percibidas como anti-capitalistas. Se trata de una práctica en construcción que batalla contra el individualismo en búsqueda de un colectivo/plural social. Esta forma de rebeldía fue, y es, confrontada desde el poder con estrategias políticas, económicas y discursivas que van desde la eliminación física y la represión abierta hasta el lanzamiento de políticas públicas proponiendo legitimar la autonomía (DINERSTEIN, 2013).

En este trabajo, se establece una afinidad electiva entre la autonomía y el principio de esperanza del filósofo alemán Ernst Bloch para definir autonomía como 'el arte de organizar la esperanza'. Es decir, el arte de prefigurar prácticas, sociabilidades y horizontes alternativos - mejores - a los del presente. Este es sin duda un proceso de 'aprendizaje de la esperanza'. La autonomía es la herramienta para la organización de este aprendizaje; es una hipótesis de resistencia que abarca el trazado de nuevos horizontes más allá de la verdad. En otro trabajo, el nombre 'movimientos de esperanza' (DINERSTEIN; DENEULIN, 2012) es dado para caracterizar justamente estos movimientos que se hallan en la búsqueda de una nueva forma de vida, más propicia para la creación de un entorno en el que los seres humanos puedan vivir con dignidad, pues la dignidad humana es incompatible con las condiciones de explotación y opresión (DINERSTEIN; DENEULIN, 2012, p. 589-590). A partir del ensayo y el error ('preguntando caminamos'), los movimientos de esperanza enfrentan al Estado y al capital, desafían las matrices 
de poder existentes y sus limitados horizontes sociopolíticos y socioeconómicos, llenan espacios y/o generan formas alternativas de trabajo cooperativo y digno, de democracia, de la tierra, de autogobierno indígena, de educación, de la relación con la naturaleza y de la política. Estas experiencias de autonomía en América Latina nos dan la oportunidad para discutir empírica y teóricamente la naturaleza y el significado de la autonomía en contextos indígenas y no indígenas, además para reflexionar sobre la epistemología y las limitaciones metodológicas para captar y entender estas experiencias.

\section{Utopía concreta}

La utopía actual no es abstracta a realizarse en el futuro sino una utopía concreta. Ernst Bloch utiliza el concepto de 'utopía concreta' para criticar al pensamiento utópico no transformador o no anticipatorio:

El único concepto aparentemente paradójico, es decir utopía concreta, es el apropiado: es decir la utopía de tipo anticipatoria que de ninguna manera coincide con la utopía abstracta sońadora ni con la inmadurez del socialismo abstracto. (1959/1986, p. 146).

El problema de la utopía abstracta o desiderata (AÍNSA, 2012, p. 21) es que se crean antes de la emergencia o maduración del sujeto que la encarne y, por lo tanto, están desprendidas del movimiento real de lucha. La utopía abstracta carece de especificidad histórica pues existe como una imaginación colectiva realizable en el futuro. La utopía concreta, por el contrario, 'recupera los contenidos de ese todavía no consiente' (AÍNSA, 2012, p. 25) como movimiento permanente y contradictorio dirigido hacia la apertura de nuevos horizontes. La función utópica de la esperanza, dice Bloch, hace que los seres humanos busquen algo más a partir de reconocer la falta. Cuando esto sucede, se embarcan en lo que el filósofo denomina 'iluminaciones anticipatorias'. La esperanza guía la acción. Bronner (1997, p. 166) observa que, para Bloch, la utopía no es algo que no existe en ningún lugar, sino que constituye un elemento de toda actividad humana, y es al mismo tiempo histórica y empírica. Siguiendo a Levitas, esta no es la versión correcta (concreta) de la utopía vis-a-vis la errónea (abstracta), pero es una 'categoría orientada en la praxis' (LEVITAS, 1997, p. 70).

Como praxis, la utopía concreta desafía los parámetros de legibilidad de la realidad dada, convirtiéndose en una forma compleja de la resistencia, que simultáneamente niega, crea, entra en contradicción con, contra, y más allá del Estado, la ley, el capital, para producir un 'excedente' intraducible en el lenguaje capitalista, patriarcal y colonial. La utopía concreta es una práctica autónoma 'en clave esperanza', a partir de la cual están surgiendo experiencias alternativas de tiempo, espacio y cooperación como política afectiva, que acercan resistencias indígenas y no indí- 
genas. Ambos tipos de resistencias con sus propias características están articulando realidades que 'todavía no han llegado a ser', pero que de todas maneras poseen la capacidad de desafiar a la forma valor. La utopía concreta navega en las venas abiertas del capital oponiéndole la esperanza desde su propio seno.

La misma contiene en su interior un espacio 'que aún no es', pero que puede anticiparse en el presente. No se corresponde completamente con la realidad, sino que se aventura más allá de los hechos. Para poner un ejemplo: los sem terra - los trabajadores rurales sin tierra creadores del "Movimiento de Trabajadores Rurales Sin Tierra" - rechazaron la 'realidad' del hambre y el latifundio y se embarcaron en una acción colectiva que se aventuró 'más allá del alambre', no solo en la forma de desalambrar y ocupar las tierras, sino en términos de aventurarse a leer la realidad dada de forma distinta a partir de conectarse con sus emociones y necesidades más profundas (como la necesidad de comer) y actuar movidos por la esperanza. La utopía concreta 'cuestiona la lectura y la demarcación de la realidad'. De dicha lectura de la realidad depende el potencial emancipador de la estrategia política, porque es allí en el que se define lo que es posible y lo que no es. Los hechos son importantes pero se refieren a una posibilidad de demarcar la realidad, que cerrada no es real sino una fantasía de los que la imponen. Lo real es un proceso abierto que contiene en su interior 'lo que todavía no existe' (BLOCH, 1971): "no hay realismo verdadero sin esta dimensión de apertura de la realidad" (p. 41). Para Bloch (1959/1986), existe un segundo concepto de verdad no factual que no coincide con los hechos, pues tenemos dos posibilidades: o morir de hambre yendo en contra de nuestro propio sentido de supervivencia o, como dice Bloch siguiendo a Hegel, 'pero para los hechos, la utopía concreta rechaza la obturación de lo político' (MENESES RAMÍREZ, 2012, p. 124), lo desobtura al cuestionar la lectura y demarcación de la realidad capitalista, patriarcal y colonial. El 'aun no' no es algo es algo factible de suceder en un futuro como se espera o se prevé sino una forma irresuelta del presente. La utopía concreta la anticipa y organiza que aguarda en la oscuridad del presente.

\section{Utopía, estado y traducción}

¿Cómo se posiciona la utopía concreta respecto del Estado? El debate sobre Estado y autonomía, retomado con el levantamiento zapatista en 1994, y que cobraría fuerza con la publicación del libro "Cambiar el mundo sin tomar el poder” de John Holloway (2002), está agotado. El libro generó dos posiciones: los defensores del cambio radical sin y con el Estado. Ambas posiciones tienen en común su foco en el Estado. Es decir, las preguntas que los guían son las mismas: qué hacemos con el Estado donde se concentra el poder y el uso de la violencia legítima e ilegítima. Para salirnos de esta dicotomía y falsa opción de 'estado si, estado no', se propuso invertir los términos del debate trasladando el enfoque 
desde el 'Estado' hacia 'las prácticas autónomas'. Esto no implica en absoluto deshacernos de la cuestión del mismo. En lugar de preguntarnos ¿se puede producir un cambio radical sin tomar el poder del estado?', los cuestionamientos son: ¿de qué manera el Estado regula, incorpora, acalla, domestica, reprime etc. las prácticas autónomas generadoras de utopías concretas?; ¿cómo traduce el Estado dichas prácticas anticipatorias a través de la política pública, el dinero y la ley?; ¡cuáles son los mecanismos de traducción de las prácticas alternativas a las lógicas institucionales?; ¡ cómo pueden estas prácticas alternativas continuar generando nuevos horizontes y formas de relaciones sociales anticipatorias de una sociedad post capitalista desde el Estado capitalista?. La pregunta de John Holloway (2002) provocó un cambio fundamental en el Marxismo contemporáneo y exigió repensar el papel del Estado en el cambio radical y la revolución. Las preguntas mencionadas aquí dan un paso adelante, poniendo énfasis en los cambios producidos por las luchas autónomas y sus prácticas emancipadoras a nivel de las instituciones estatales y de las dificultades de mantenimiento y desarrollo de la utopía concreta, concibiendo al estado y la ley como mediaciones en la creación de la forma específica e histórica que adquiere la utopía concreta.

En esas preguntas, el Estado no es un objeto a 'tomar' sino una mediación en la creación de las utopías concretas. Él las traduce permanentemente en formas de participación y práctica sociales que pueden subordinarse a la lógica capitalista y colonial. ¿Qué quiero decir con 'traduce'? Haciendo referencia a la violencia epistémica de la modernidad, Vázquez (2011, p. 36) observa que ésta "hace invisible todo lo que no entra en los 'parámetros de legibilidad' de su territorio epistémico". Parafraseando al autor, podemos afirmar que el estado delinea los 'parámetros de legibilidad' de la realidad a partir de la cual las otras realidades alternativas son invisibilizadas. La utopía concreta rechaza el campo de certeza real creado por el Estado dentro de la cual ella siempre es despojada de su sentido crítico y transformador.

\section{Negación, creación y contradicción: dimensiones de la utopía concreta}

¿Cómo pueden estas prácticas concretas producir una ruptura en la realidad del capitalismo patriarcal y colonial? Se utilizan aquí cuatro ideas de la filosofía de Ernst Bloch para poner a la autonomía en clave de esperanza y poder señalar las diferentes dinámicas desarrolladas al interior de estas prácticas utópicas concretas.

Primero, en toda utopía concreta existe un proceso de negación. La posibilidad de negar colectivamente reside en el hecho de que el mundo es inconcluso y abierto. Si así no lo fuera, nada podría ser alterado. Lo real es siempre un proceso y por ende nos provoca a pensar más allá 'Lo real', sugiere Bloch (1959/1986), "es una mediación entre el presente, un pasado inconcluso 
y, sobre todo, un futuro posible" (p. 196-197). El jya basta! zapatista fue un momento de negación que operó como bisagra entre dos historias: existe un antes y un después del no. Esta praxis negativa expresada en la protesta, o sea, la oposición, el desacuerdo, el antagonismo, es necesaria pues sin criticar lo dado no se puede emerger lo nuevo. El ya basta recuperó la voz de los invisibilizados y revierto las reglas del juego de la subordinación. No al Tratado de Libre Comercio de América del Norte (NAFTA), al gobierno mexicano, al poder político y económico, a la globalización o guerra contra la humanidad, al dinero como la internacional del terror. Propusieron, en palabras del ex subcomandante Marcos, la internacional de la esperanza. Esta se alzó en Chiapas como negación, contra la desilusión y la decepción generadas por el neoliberalismo como una máquina de matar sueños sociales.

Segundo, la construcción de la utopía concreta contiene una dimensión de creación inseparable de la de negación. La función utópica de la esperanza nos permite experimentar una vida mejor aun cuando no sepamos ni cómo ni cuándo. Nuestra conciencia anticipatoria nos permite sońar y crear nuevas realidades. En Argentina, durante el año de 2001, el rechazo explosivo de violencia de la estabilidad neoliberal en el marco de una crisis profunda y total (momento de negación) organizó un proceso de apertura de nuevos espacios, prácticas y gramáticas radicales realzadas por ideas de dignidad y democracia horizontal, generando un léxico que no existía en la izquierda tradicional. Se escapó también de la política identitária tradicional, creando identidades abiertas y de lucha que atravesaron diversas clases sociales.

Tercero, la utopía concreta cobija en su interior una dinámica contradictoria porque se desarrolla al interior, y no por fuera, de la sociedad capitalista. Por ello, la utopía concreta puede fracasar. Lo que todavía no ha llegado a ser no puede movilizarse, organizarse y visibilizarse a través del aislamiento de los movimientos y su reclusión a un espacio autonomizado e impenetrable (error común en las interpretaciones 'anarquistas' y 'autonomistas' de la autonomía), ni a través de la consolidación del proyecto autónomo en el Estado (error común de las versiones más populistas de la autonomía). La esperanza se 'organiza' por medio de la resistencia y del relacionamiento activo (antagónico, doloroso, conflictivo y/o complaciente) con las formas institucionales, pues éstas median la construcción autonómica, a la vez que la autonomía debe alterarlas y/o destruirlas para convertirse en subjetividad emancipadora. Existe una tensión al interior de toda utopía concreta, entre rebelión e integración, dentro de la (im) posibilidad de la construcción de utopía a través de la praxis autónoma, existe la posibilidad de que las prácticas autónomas desafíen la misma hegemonía a la que pertenecen (BÖHM; DINERSTEIN; SPICER, 2010). Por lo tanto, puede ser desilusionada. 
En su conferencia inaugural en la Universidad de Tübingen, en 1961, titulada “¿Puede ser decepcionada la esperanza?”, Bloch habló de la necesidad de la decepción: "La esperanza debe ser incondicionalmente desilusionable, porque está abierta en una dirección orientada al futuro" (BLOCH, 1998, p. 340). Ella no es contemplativa e ingenua; no está asegurada; es azar y contingencia, está rodeada de peligro. La utopía concreta está siempre a riesgo de ser integrada a la lógica del capital y del Estado y de las nuevas formas de colonialidad del poder, como la política de multiculturalismo. La esperanza es crítica y debe ser decepcionable.

El siglo 21 comenzó en América Latina con múltiples procesos de apropiación estatal de la autonomía. La emergencia de nuevos movimientos rurales y urbanos indígenas y no indígenas produjo en muchos de los países latinoamericanos cambios políticos de magnitud, y dio lugar a lo que Matta denominó 'rito de inversión', es decir, un proceso en el que la gente organizada ocupó el espacio del que se la había excluido. La llegada al poder de la centro-izquierda progresista provocó el movimiento contrario, lo que Matta en este caso denomina 'rito de reforzamiento' por el cual los líderes políticos se apropian nuevamente del poder de la autonomía en una configuración política, que les permite transformarse en nuevos depositarios de esperanza del pueblo (MATTA apud PLOTKIN, 1995, p. 215).

La apropiación estatal de la autonomía inició un proceso de traducción de las prácticas autónomas para su incorporación a la agenda estatal como elemento vital al logro de la nueva estabilidad de los gobiernos progresistas. ¿La integración del Sumak Kawsay a la Constitución Nacional de Ecuador fue bienvenida, pero no tradujo acaso la cosmología indígena en el lenguaje del 'desarrollo', cuando las comunidades indígenas rechazan la idea de desarrollo de plano? Estas traducciones juegan un papel primordial en el avance de las contradicciones que subyacen a la construcción de utopías concretas. En Brasil, el gobierno de Lula facilitó la traducción de las agrovilas del Movimento dos Trabalhadores Rurais Sem Terra (MST) al lenguaje del Banco Mundial, que las denominó 'huertas familiares' convirtiendo así el sueño de la reforma agraria popular de los sem terra en un instrumento de la descentralización neoliberal y del enriquecimiento de Monsanto que, bajo las directivas económicas del Banco Mundial, vieron en las cooperativas de agricultores un espacio para el agronegocio. Estas no han sido 'impuestas' desde arriba sino producidas a través de luchas, encuentros, negociaciones y desencuentros entre el estado-gobierno y los movimientos, generando la 'institucionalización conflictiva' de la autonomía en el Estado (DINERSTEIN; CONTARTESE; DELEDICQUE, 2010).

El Estado es una mediación de la lucha de los movimientos por constituirse en subjetividad emancipadora, no nos referimos a la función estatal de regulación o dominación ejercida externamente sobre los sujetos sino a su función constitutiva del proceso de producción de subjetividad. El Estado es una forma de existencia de las relaciones antagónicas, que no elimina las inconsistencias de di- 
chas relaciones sino que permite que existan. Él es en sí mismo un espacio de contradicción (THWAITES REY, 2004). Por ello, el análisis del Estado, las leyes y la economía deben estar subordinados a otro eje del debate sobre la autonomía que se traslade desde 'movimientos versus Estado', hacia 'subjetividades conformistas versus no conformistas' (SANTOS, 2003) dentro del movimiento de resistencia, mediadas por el Estado.

\section{La cuarta dimensión: el 'excedente'}

¿Y la cuarta dimensión? Debemos ahora dar un giro de 360 grados y preguntarnos: ¿Está la utopía concreta sumergida en una lucha constante entre rebelión y institucionalización, o existe algo más? El término (im)posibilidad de la utopía refiere al hecho de que la autonomía no puede ser completamente realizada ya que el Estado y el capital buscaran continuamente recuperarla, difícilmente sea está totalmente asimilada a las instituciones existentes (BÖHM; DINERSTEIN; SPICER, 2010). Entonces, ¿qué es lo que permanece intraducible, fuera del alcance de la traducción estatal? Esta pregunta nos obliga a retomar el concepto de 'aún no' y explorar una cuarta dimensión o dinámica al interior de la utopía concreta: la dimensión del excedente intraducible perteneciente a la dimensión del aún no. ¿De qué se trata este excedente, y como captarlo para poder recuperarlo como dimensión central de la 'organización de la esperanza'?

Primero, si bien muchos aspectos de la resistencia de estos movimientos fueron incorporados a la lógica estatal de los gobiernos progresistas, el 'aun no' radicado en el interior de la utopía concreta movilizada por la esperanza se refiere a una dimensión innombrable, invisible, sin imagen, no empírica y, por ende, inintegrable a la lógica del poder. La radicalidad de la autonomía colectiva emerge de su capacidad práctica de embarcarse y pilotear esta tensión, ya que de ella emergerán 'grietas' (HOLLOWAY, 2010) en la 'realidad' capitalista desde donde se ensayan nuevas realidades (DINERSTEIN, 2013).

Segundo, lo que no puede traducirse en gramática estatal no puede ser captado por las categorías de la economía política. Se requiere de una crítica a la economía política, es decir una crítica a las abstracciones formales de la economía política que naturalizan a la sociedad capitalista, pues despojan a las categorías de la lucha que representan. Estas no son abstracciones formales, o sea descripciones de lo que existe, sino reales, las categorías que son productos de la misma lucha material e histórica que atraviesan las relaciones sociales que estas categorías designan.

Tercero, vista en clave esperanza, la crítica de Marx a la economía política se transforma en una crítica 'pre-figurativa'. Leída desde el principio esperanza, ésta no solo se revela la realidad oculta del valor sino como el valor, como forma de dominación, también es permanentemente confrontado por la esperanza desde el 
interior de los procesos de valorización. El arte de organizar la esperanza navega en las venas del capital re-sensualizando, uniendo lo que ha sido separado, aportando materialidad, poniendo el cuerpo, dándole voz a lo que ha perdido como resultado de la auto expansión del valor.

Aunque el capitalismo parezca un sistema sólido, sabemos que el valor como tal es un concepto que designa una realidad no realizada materializada solo en la forma de dinero. La substancia del valor es el trabajo abstracto, es decir una medida de tiempo de trabajo socialmente necesario que es abstraída de su humanidad. El dinero anticipa en el presente el valor que se realizará en el futuro. Siguiendo a Bonefeld, Marx no sólo habla de 'objetividad fantasmagórica' o 'pura objetividad fantástica', sino que también dice que el valor es 'invisible' en la mercancía (BONEFELD, 2010, p. 266). Bellofiore (2009) es rotundo: hablando en sentido estricto, el valor es un fantasma que solo adquiere materialidad en la forma de dinero. A pesar de que su sustancia es una abstracción, el valor se expande hacia toda la sociedad y deviene, como dice Negri (1991), "la forma más simple y pura de la política". El valor entonces es una realidad no materializada y no empírica que tiene un gran poder sobre la sociedad; es una realidad no materializada y no empírica que tiene un gran poder sobre la sociedad.

Pensemos ahora en el principio de esperanza de Bloch. La esperanza es una emoción humana que se compromete con una realidad que todavía no existe para echar luz a la oscuridad del presente. Pero cuando se organiza, ella se materializa en acciones concretas que articulan demandas, sueńos colectivos y acciones políticas. Tanto la forma valor como la esperanza existen más allá de los parámetros de legibilidad de la "realidad". Como procesos invisibles y antagónicos, se mueven en direcciones opuestas: mientras que el capital es valor en el movimiento, la esperanza es anti-valor en movimiento. Lo que está en juego, entonces, es la posibilidad de construir la realidad del valor, es decir lo que está en juego en esta lucha no empírica es el contenido de lo que todavía no ha llegado a ser: ¿la realización del valor o de la esperanza?

\section{La lucha entre el valor y la esperanza: visualizando la utopía}

Esta lucha entre valor y esperanza y la producción de utopías concretas al interior de los procesos de valorización pueden visualizarse con una fórmula distinta. El circuito de reproducción del capital es representado por la fórmula D-M-D' (Dinero - Mercancía - Dinero prima). La transformación del capital en su forma más abstracta (dinero) es representada por D-D' (Dinero-Dinero prima). La ausencia de $\mathrm{M}$ indica que el capital se ha retirado del circuito productivo, para reproducirse especulativamente. La idea de auto-expansión del capital en su forma dinero representada en la ecuación D-D' 
no permite imaginar qué sucede al interior del proceso en el cual D-M-D' se transforma en D-D'. Se trata de una fórmula que representa un proceso no humano de 'producción' y consumo de mercancías. Sin embargo, como mencionado anteriormente, la crisis del capital en su forma dinero D-D' proporciona un escenario para una lucha en un terreno no empírico, que las ciencias sociales confunden con 'exclusión social'. A menos que reconozcamos este espacio de subjetivación como una realidad no empírica, será difícil pensar en las trabajadoras desocupadas como subjetividad rebelde.

Para ilustrar estas formas de utopía concreta generadas en el proceso de valorización del capital, aceleradas en las crisis del mismo, D-D' puede ser reemplazada por D-a; b; g; d-D', en el que las letras a, b, g y d representan las formas creadas en el proceso de valorización del capital; D-a; b; g; d-D’ permiten visualizar, en primer lugar, el proceso de valorización del ficticio como espacio de subjetivación y, en segundo lugar, a las utopías concretas como formas de lucha y creación de realidades alternativas. D-a...b...g...d...-D’ incluye no sólo a aquellos que son directamente explotados en las fábricas, sino a aquellos que están en parte o completamente excluidos de ellas, a aquellos que no participan directamente del proceso de producción pero si de la vida de la polis y producen otras formas organizacionales, identitárias o relacionales que las fábricas, abriendo así otros espacios para construir lazos solidarios y acción política.

La ecuación propuesta nos obliga a pensar en el potencial anticipatorio de cada una de estas formas de lucha y utopía dentro del conjunto, sin necesidad de establecer prioridades y jerarquías como formas pluriversales que anticipan relaciones post capitalistas, post coloniales y post patriarcales. En D-a; b; g; d-D' se observan claramente tres cosas: D' depende en última instancia de la subsunción humana al circuito de reproducción del capital; las subjetividades son creadas al interior de dicho proceso y por ello la resistencia reside en el corazón (y no fuera) de la relación del capital y cada una de estas formas de existir y resistir poseen la capacidad de desafiar algunas de las instancias del circuito de valorización (y por ende de dominación política). En este momento de crisis, la utopía presenta una barrera a los procesos de valorización del capital que puede erosionarlo desde adentro. La fórmula correcta con final inacabado para representar esto sería: D-a;b;g;d...-?

¿Es esta fórmula adecuada para comprender el excedente producido por las utopías concretas en el caso de movimientos indígenas?

\section{Especificad indígena y las fallas de la teoría}

En las últimas dos décadas, los movimientos indígenas han hecho más visibles y fuertes en las luchas globales por la justicia social, en particular contra 
las nuevas políticas económicas basadas en el extractivismo, en la apropiación de tierras y en la privatización de los ejidos. Esta transformación en el activismo indígena ha despertado el interés y la simpatía de activistas investigadores-activistas, muchos de ellos anarquistas y marxistas autónomos, los cuales en general interpretan la política indígena de manera tal que dejan de lado su especificidad, reproduciendo así la colonialidad a la que los movimientos indígenas se están oponiendo. Las particularidades de la resistencia indígena no se refieren simplemente a las diferencias culturales o distinciones en los antecedentes históricos o el contexto de la producción, sino a una forma alternativa de política y de un posicionamiento históricamente diferenciado de los pueblos indígenas vis-à-vis el Estado, la ley y el capital, en la economía mundial. Como sugiere Grosfoguel (2008), en el intento válido de encontrar puntos en común, las diferencias son subestimadas y los análisis se vuelven inevitablemente superficiales y viciados por el uso de la terminología eurocéntrica (GROSFOGUEL, 2008).

El enfrentamiento entre conocimientos rivales desde el Norte y el Sur ha sido expuesto en el Foro Social Mundial (FSM) (SANTOS, 2005, p. 22) y ha hecho estas diferencias evidentes. Se requiere que prestemos atención a este problema, no descartando teorizaciones radicales sobre el cambio social y la autonomía producidas en el Norte, pero señalando el problema de su universalización. Queda claro que no podemos partir de las ideas y conceptualizaciones generadas en los centros de poder, y mucho menos en el mundo académico, porque esto reproduciría una forma de pensamiento que atribuye el monopolio de los conocimientos científicos al Norte y la invisibilización de los conocimientos alternatives producidos del "otro lado" de la demarcacion occidental. Santos (2007) sugiere superar el pensamiento abismal, es decir

el pensamiento occidental moderno es un sistema de distinciones visibles e invisibles, las invisibles son el fundamento de las visibles. Las distinciones invisibles se establecen a través de líneas radicales que dividen la realidad social en dos reinos, el reino de 'este lado de la línea' y el reino de 'el otro lado de la línea'.

La división es tal que 'el otro lado de la línea' se desvanece como realidad, se vuelve inexistente. Lo que se produce como inexistente se excluye radicalmente, ya que está más allá del ámbito de lo que la concepción aceptada de inclusión considera su otro. Lo más fundamental acerca del pensamiento abismal es, pues, la imposibilidad de la co-presencia de los dos lados de la línea (SANTOS, 2007, p. 1).

Para superar este pensamiento, hace falta comprender la especificidad de la lucha indígena. Los pensadores decoloniales sostienen que es indispensable 'superar tanto el eurocentrismo como el fundamentalismo del Tercer Mundo' (GROSFOGUEL, 2008) para terminar el 'epistemicidio' (SANTOS, 2007). 
Para los estudiosos decoloniales, el mundo es 'pluriversal' (CONWAY; SINGH, 2011, p. 702). Este concepto impugna la idea de universalidad de las formas occidental-céntricas de conocimiento silenciadoras de la otra, colonial, a través de sus reivindicaciones propias de universalidad, con el rechazo sistemático de su propia particularidad histórica-geográfica, su descrédito de otros conocimientos como no científicos y sus narrativas del surgimiento de la modernidad como un proceso interno a Europa. Este 'etnocentrismo epistémico' requiere 'redefinir la retórica emancipadora de la modernidad desde las cosmologías y epistemologías de lo subalterno, que se encuentran en el lado oprimido y explotado de la diferencia colonial hacia una lucha de liberación colonial de un mundo más allá de la modernidad eurocéntrica' (GROSFOGUEL, 2008, p. 13). Mignolo (2000) plantea un 'pensamiento fronterizo crítico' para 'impensar' las ciencias sociales (LÓPEZ SEGRERA, 2000). Sin embargo, una indeterminación fundamental en la perspectiva decolonial consiste en su falta de consideración de los procesos materiales de constitución de la pluriversalidad, los cuales proponen en el marco de los procesos de intensificación de la subsunción de la sociedad global a las fuerzas del capital. Su interpretación del marxismo como una 'economía política' y no como una crítica de la economía política (y menos aún como una crítica prefigurativa a la economía política propuesta anteriormente les impide captar la dinámica en la cual se basan las diferencias dentro de la fuerza universalizante del capital).

\section{Subsunción real en el caso indígena: subsunción por exclusión}

¿De qué manera se posicionan los pueblos indígenas en relación a los procesos de acumulación del capital? ¿En qué medida se han transformado la integración y subsunción del mundo indígena con el desarrollo del capitalismo y en particular el capitalismo actual basado en la acumulación por despojo (HARVEY, 2005)? ¿Cómo podemos teorizar estas diferencias con el fin de conceptualizar las contradicciones que emergen de la lucha por la libre determinación indígena?

La característica más importante del capitalismo actual no es la incorporación de trabajadores en el proceso productivo, al cual claramente la población indígena del mundo no ha sido completamente integrada, sino la subsunción real, o sea la subsunción de toda actividad humana a la lógica expansiva del valor, de naturaleza invisible. La forma específica tomada por la subsunción de los pueblos indígenas en las relaciones sociales capitalistas es diferente de la población no indígena y, por lo tanto, ha sido un importante punto de discusión entre los estudiosos de los estudios subalternos (ES) y la escuela decolonial. Su argumento es que las poblaciones indígenas no han sido integradas al mercado internacional o solo formalmente, a la vez que ellas fueron oprimidas y invisibilizadas (SANTOS, 2007). El mundo indígena se interpreta 'fuera' del capital. Sin embargo, este argumento parece insostenible dada la fuerza universalizante del capital global. 
Chibber (2013) sostiene que los ES confunden 'universalización' del capital con 'homogeneización de las relaciones del poder' (CHIBBER, 2013, p. 150), con la excepción de Chakrabarty, quien afirma que el capitalismo ha fracasado en su misión universalista (CHIBBER, 2013, p. 133). Universalización del capital no es lo mismo que la homogeneización de las relaciones de poder. Chibber sostiene que 'lo que el capitalismo universaliza es una estrategia particular de reproducción económica' (2013, p. 111) e indica que si la universalización del capital y homogeneización de las relaciones de poder en el Oeste y el Este están desacopladas, podemos darnos cuenta fácilmente que la universalización no sólo permite que las diferencias existan, sino que los promueve, por ser beneficiosas para la expansión del capital. Entonces, las formas específicas de las relaciones políticas, de poder y de clase, pueden co-existir con la auto-expansión del capital global como un proyecto universal. Como vimos, la característica más importante del capitalismo no es la incorporación de la clase trabajadora al proceso de producción, pero es la constante subordinación del trabajo concreto en trabajo abstracto. Esto no es una categoría abstracta sino una medida del trabajo socialmente necesario requerido en determinado momento histórico para la producción del valor. El trabajo abstracto constituye la sustancia del valor. Lo que importa para mantener al capital como forma de la sociedad humana es el tiempo de trabajo socialmente necesario, aquel abstraído del trabajo concreto realizado por trabajadoras individuales para empresas particulares en determinadas ramas de la industria: es el trabajo abstracto que constituye la sustancia del valor. La segunda característica del capitalismo entonces es la subsunción real. En la formal, el trabajo concreto se subordina directamente al capital (MARX, 1990, p. 1034), cuando este "todavía no se había convertido en la fuerza dominante, capaz de determinar la forma de la sociedad en su en su conjunto" (MARX, 1990, p. 1023). Sin embargo, la transición de la subsunción formal a la real que produjo la industrialización, y se expandió con el capital global, significó que "todo el desarrollo del trabajo socializado [...] en el proceso inmediato de producción, tomara la forma productiva del capital" (MARX, 1990, p. 1024). Como sostiene Negri,

el capital subsume progresivamente todos los elementos y materiales del proceso de circulación (dinero y intercambio en el primer lugar, como funciones de mediación) y, a partir de entonces, todas las relacionadas con el proceso de producción, por lo que en ese momento se funda el paso desde la producción a la fábrica social. (1991, p. 114).

La subjetividad del trabajo ya no se somete externamente por capital, sino que se integra en él.

Si aceptamos las dos características del capitalismo agravadas por los procesos de financiarización y la llamada biopolítica, podemos afirmar que mientras la persistencia del colonialismo en forma de "colonialidad del poder" 
(QUIJANO, 2000) y las diferencias socioeconómicas, políticas y culturales entre el Oeste, Este, Norte y Sur persisten, la discusión sobre la autonomía de las poblaciones indígenas y sus formas prefigura de sociedades alternativas requier la pregunta acerca de las formas en que la subsunción real ha transformado la posición de los pueblos indígenas en el mundo global del capital, sobre todo desde la década de 1970.

Se argumenta aqu que la subsunción real del mundo indígena presenta un caso particular de la subsunción real, denominado subsunción por exclusión. Por subsunción real por exclusión, se entiende que la opresión racial y la invisibilización son condiciones necesarias para la expansión del valor. La subsunción real por exclusión delinea una forma diferente de (no) integración de las poblaciones indígenas en el capital. La exclusión es una expresión fenomenológica de una experiencia de subsunción real de las cosmologías indígenas, que se vuelven invisibles en la medida en que son incompatibles con los parámetros de legibilidad de la realidad. Subsunción por exclusión designa un caso particular de la subsunción real del trabajo y de la sociedad en el capital que, si bien formar parte de la valorización del capital proceso, alcanza la forma fenomenológica de 'exclusión'. La noción de 'subsunción real por la exclusión' nos permite resaltar la importancia de las cosmologías indígenas como una amenaza interna a la fuerza universalizante del capital, por un lado, y para reconocer trayectorias particulares de prefiguración de otras realidades, por el otro lado.

\section{A modo de conclusión: el arte de organizar la esperanza}

La esperanza es una fuerza esencial en todo el proceso de resistencia contra el poder. Pero no es nada nuevo, sin esperanza no hay cambio. Sin embargo, vivimos en un tiempo en que la utopía ya no puede ser objetada, pero necesitamos discutir más de qué tipo de utopía estamos hablando. La autonomía colectiva da forma a lo (im)posible, a lo que todavía no ha llegado a ser, como trabajo digno, soberanía alimentaria, autogobierno y auto-organización. No se tratan de utopías localizadas en el futuro, 'reales', es decir, realizables o meras 'fantasmagorías', sino 'fantasías determinadas' que implican un ser que todavía no es de naturaleza esperable, es decir, que anticipa lo posible real (BLOCH, 2004 p. 181). La función utópica de la esperanza 'altera la temporalidad pasado-presente-futuro, al articular la posibilidad del futuro en el presente' y por ello podemos llamar a estos de movimientos 'movimientos esperanza'. La 'realidad' de la autonomía colectiva no es objetiva y conmensurable, sino que es: 'inasequible a aquel esquematismo que lo sabe todo de antemano y que tiene por realidad sus esquemas uniformes e incluso formalistas'. La realidad, dice Bloch, 
no está completa sin posibilidad real, y el mundo sin propiedades grávidas de futuro no merece [...] ni una mirada, ni un arte, ni una ciencia. [La] utopía concreta se encuentra en el horizonte de toda realidad ([1959] 2004, p. 181).

Caminando hacia el Novum, no linealmente, los 'movimientos esperanza' hacen evidente que es realmente posible prefigurar nuevos o añorados horizontes colectivos arraigados en la memoria de distintas historias y tradiciones de lucha. Estas son utopías concretas pluriversales y pueden ser desilusionadas en cualquier momento. La cuestión de la posibilidad de desilusión es importante a la hora de interpretar momentos de 'derrota' o repliegue. Mientras muchos de los que quieren cambiar el mundo dudan de la importancia política de los movimientos autónomos por su ineficiencia en modificar las lógicas del poder, desde el poder se advierte absolutamente la fuerza que poseen los sueños colectivos. Prueba de ello son las represiones violentas y las masacres perpetuadas durante las luchas contra el neoliberalismo. Cualquier estrategia para los movimientos y la organización política requiere la recuperación de la esperanza no como fantasía o deseo, sino como la convicción de que existe una realidad no realizada en toda realidad y que la lucha política contiene otra lucha invisible, en el que se disputa el contenido de lo que no es, día a día. La esperanza, asevera Bloch, "da amplitud a [la gente] [...] el trabajo de esta [emoción] [les] exige que se entreguen activamente al proceso del devenir al que ellos mismos pertenecen" (2004, p. 26). La utopía concreta es una búsqueda permanente por ese lugar donde, parafraseando a Bloch, "el sujeto se convierte en predicado". En definitiva, el arte de organizar la esperanza simplemente nos posiciona en el único lugar desde donde podemos cambiar el mundo, es decir, ese momento que todos conocemos, antes del amanecer, 'cuando todavía no ha salido el sol, pero ya no es de noche' (BRONNER, 1997, p. 177).

\section{REFERENCIAS}

AÍNSA, F. El principio esperanza desde América Latina. In: MENESES, J. M.; MARTÍNEZ ANDRADE, L. (Comp.). Esperanza y utopia. Ernst Bloch desde América Latina. México: Taberna Librería Editores, 2012. p. 21-40.

BELLOFIORE, R. A Ghost Turning into a Vampire. In: BELLOFIORE R.; FENISCHI, R. (Eds.) Re-Reading Marx. London: Palgrave Macmillan, 2009. p. 178-194.

BLOCH, E. El principio esperanza. Madrid: Editorial Trotta, 2004.

Can hope be disappointed?. In: . Literary Essays. Stanford, CA: Stanford University Press, 1998. p. 339-345.

. The principle of hope. Cambridge, MA: The MIT Press, 1986.

. On Karl Marx. New York: Herder and Herder, 1971. 
BÖHM, S.; DINERSTEIN, A.C.; SPICER, A. The (Im)possibilities of autonomy. Social movements in, against and beyond the State, Capital and Development. Social Movement Studies, v. 1, n. 9, p. 17-32, 2010.

BONEFELD, W. Abstract labour: against its nature and on its time. Capital \& Class, v. 34, n. 2, p. 257-276, 2010.

CHIBBER, V. Postcolonial theory and the specter of capital. London - New York: Verso, 2013.

CONWAY, J.; SINGH, J. Radical democracy in global perspective: notes from the pluriverse; Third World Quarterly, v. 32, n. 4, p. 689-706, 2011.

DINERSTEIN, A.C. The politics of autonomy in Latin America. The Art of Organising Hope. Aldershot-New York: Palgrave MacMillan, 2015.

- La autonomía y sus imaginarios prácticos en permanente construcción (Introducción). In: Movimientos sociales y autonomía colectiva: la política de la esperanza en América Latina. Buenos Aires: Capital Intelectual, 2013. p. 23-37.

DINERSTEIN, A. C.; DENEULIN, S. Hope movements: naming mobilization in a post-development world. Development and Change, v. 43, n. 2, p. 585-602, 2012.

DINERSTEIN, A. C.; CONTARTESE, D.; DELEDICQUE, M. La ruta de los piqueteros. Luchas y Legados. Buenos Aires: Capital Intelectual, 2010.

GROSFOGUEL, R. Transmodernity, Border thinking and global coloniality. Decolonising political economy and postcolonial studies. Eurozine, 2008. Disponible en: $<$ http://www. eurozine.com/articles/2008-07-04-gros-foguel-en.html>. Acceso en: 29 jun. 2015.

HARVEY, D. The new imperialism. Oxford: Oxford University Press, 2005.

HOLLOWAY, J. Crack capitalism, London: Pluto Press, 2010.

Change the world without taking power: the meaning of revolution today. London: Pluto Press, 2002.

KAMINSKY, G. Spinoza: la política de las pasiones. Barcelona: GEDSA, 1998.

LANDER, E. (Ed.) La colonialidad del saber. Eurocentrismo y ciencias sociales. Perspectivas latinamericanas. Buenos Aires: CLACSO, 2000, p. 177-200.

LAZZARATO, M. La fábrica del hombre endeudado. Ensayo sobre la condición neoliberal. Buenos Aires: Amorrortu, 2013.

LEVITAS, R. Educated hope: Ernst Bloch on abstract and concrete utopia. In: DANIEL, J. O.; MOYLAN, T. Not yet: reconsidering Ernst Bloch. London and New York: Verso, 1997. p. 65-79.

LÓPEZ SEGRERA, F. Abrir, impensar y redimensionar las ciencias sociales en América Latina y el Caribe. In: LANDER, E. (Ed.) La colonialidad del saber. Eurocentrismo y ciencias sociales. Perspectivas latinoamericanas. Buenos Aires: CLACSO, 2000. p. 177-200.

MENESES RAMÍREZ, J. M. Ernst Bloch: la soberanía del sueño. In: MENESES, J. M.; MARTÍNEZ ANDRADE, L. (Comp.). Esperanza y utopía. Ernst Bloch desde América Latina. México: Taberna Librería Editores, 2012. p. 121-140. 
MIGNOLO, W. Local Histories/Global Designs: coloniality, subaltern knowledges, and border thinking. USA: Princeton University Press, 2000.

NEGRI, A. Marx beyond Marx: lessons on the Grundrisse. New York: Autonomedia, 1991.

PLOTKIN, M. Rituales políticos, imágenes y carisma: la celebración del 17 de octubre y el imaginario Peronista 1945-1951. In: TORRE, J. C. (Comp.) El 17 de Octubre de 1945. Buenos Aires: Ariel, 1995. p. 171-218.

PORTO-GONÇALVES, C. W.; LEFF, E. A ecologia política na América Latina: a reapropriação da natureza, a reinvenção dos territórios e a construçáo da racionalidade ambiental. Desenvolvimento e Meio Ambiente, v. 35, p. 65-88, 2015.

QUIJANO, A. Colonialidad del poder, eurocentrismo y América Latina. In: LANDER, E. (Ed.) La colonialidad del saber. Eurocentrismo y ciencias sociales. Perspectivas latinoamericanas. Buenos Aires: CLACSO, 2000. p. 177-200.

SANTOS, B. S. Beyond abyssal thinking. From global lines to ecology of knowledges. Eurozine, 2007. Disponible en: <http://www.eurozine.com/articles/2007-06-29-santosen.html>. Acceso en: 29 jun. 2015.

. The future of the world social forum: the work of translation. Development, v. 48, n. 2, p. 15-22, 2005.

Crítica de la razón indolente: contra el desperdicio de la experiencia. Bilbao: Desclee de Brouwer, 2003.

THWAITES REY, M. La autonomía como búsqueda, el estado como contradicción. Buenos Aires: Prometeo, 2004.

VÁZQUEZ, R. Translation as erasure: thoughts on modernity's epistemic violence. Journal of Historical Sociology, v. 24, p. 27-44, 2011.

Recibido en 12 de Abril de 2016.

Aprobado en 17 de Abril de 2016. 